\title{
ANALISIS KETEBALAN LAPISAN SEDIMEN DAN INDEKS KERENTANAN SEISMIK KOTA JAMBI BAGIAN TIMUR
}

\author{
Arie Satria $^{1}$, Ichy Lucya Resta ${ }^{2}$, Nasri Muchtar ${ }^{3}$ \\ ${ }^{1,2,3}$ Program Studi Teknik Geofisika, Fakultas Sains dan Teknologi Universitas Jambi
}

Corresponding author: mr.ariesatria12@gmail.com

Manuscript received: Jan 22 ${ }^{\text {nd }}$, 2020, revised: Jan 31 ${ }^{\text {st }}$, 2020;

Approved: Mar 09th 2020 ; Available online : Mar 20 ${ }^{\text {th }}, 2020$

\begin{abstract}
Abstrak - Telah dilakukan penelitian tentang ketebalan lapisan sedimen dan indeks kerentanan seismik Kota Jambi bagian timur. Penelitian ini bertujuan untuk mengetahui pengaruh ketebalan lapisan sedimen terhadap indeks kerentanan seismik di Kota Jambi bagian timur berdasarkan data mikrotremor. Pengambilan data mikrotremor sebanyak 25 titik penelitian yang tersebar di daerah penelitian. Pengolahan dilakukan menggunakan metode HVSR (Horizontal to Vertical Spectra Ratio) untuk memperoleh kurva H/V. Kurva tersebut mereprentasikan nilai frekuensi alami $\left(f_{0}\right)$ dan faktor amplifikasi $\left(\mathrm{A}_{0}\right)$. Berdasarkan pengolahan data diperoleh nilai indeks kerentanan seismik $(\mathrm{Kg})$ berkisar antara 0.70 $20.18 \times 10^{-6} \mathrm{~cm}^{2} / \mathrm{s}$ dan ketabalan lapisan sedimen berkisar antara $16.46-61.45$ meter. Hasil penelitian menunjukkan bahwa distribusi nilai indeks kerentanan seismik $(\mathrm{Kg})$ berkolerasi relatif baik terhadap ketebalan lapisan sedimen daerah penelitian. Zona dengan indeks kerentanan seismik $(\mathrm{Kg})$ tinggi relatif berasosiasi pada endapan alluvial dengan ketebalan lapisan sedimen lebih dari 30 meter. Zona tinggi tersebut terkonsentrasi pada kelurahan Pasir Panjang, Tanjung Raden hingga bagian selatan Olak Kemang kecamatan Danau Teluk dan Tanjung Sari kecamatan Jambi Timur.
\end{abstract}

\begin{abstract}
This research was carried out about of sediment layer thickness and seismic vulnerability index in eastern Jambi City. This research was aimed to determine the effect of sediment layer thickness on seismic vulnerability index in eastern Jambi City based on microtremor data. Acquisition research data of microtremor was 25 points spreading in the area. Processing data was analyzed by HVSR (Horizontal to Vertical Spectra Ratio) method to obtain the H/V curve. This curve represents the value of the natural frequency $\left(\mathrm{f}_{0}\right)$ and the amplification factor $\left(\mathrm{A}_{0}\right)$. Based on data processing obtained, the seismic vulnerability index $(\mathrm{Kg})$ value ranges 0.70 to $20.18 \times 10^{-6} \mathrm{~cm}^{2} / \mathrm{s}$ and the sediment layer thickness (h) value ranges 16.46 to 61.45 meters. The results showed that the distribution of the seismic vulnerability index $(\mathrm{Kg})$ correlated relatively well with the sediment layer thickness of the research area. The high zone of seismic vulnerability index $(\mathrm{Kg})$ is relatively associated with alluvial deposits and also the sediment layer thickness of more than 30 meters. The high zone of seismic vulnerability index $(\mathrm{Kg})$ is concentrated in Pasir Panjang, Tanjung Raden to Olak Kemang in Danau Teluk sub-district and Tanjung Sari in Jambi Timur sub-district.
\end{abstract}

Keywords - Microtremor, sediment layer thickness, seismic vurnerability index

How to cite this article:

Satria, A., Resta, I.L., dan Muchtar, N., 2020, Analisis Ketebalan Lapisan Sedimen dan Indeks Kerentanan Seismik Kota Jambi Bagian Timur, Jurnal Geofisika Eksplorasi, 6 (1) p.18-30. doi: 10.23960/jge.c6i1.58

\section{PENDAHULUAN}

Kota Jambi merupakan ibu kota provinsi Jambi yang sedang berkembang terutama dibidang pembangunan infra- stuktur jalan dan gedung bertingkat. Dalam pembangunan dan pengembangan kota perlu memperhatikan beberapa hal meliputi kekuatan dan kualitas bangunan, kondisi geologi dan geotektonik 
lokasi bangunan serta percepatan tanah lokal (Edwiza dan Novita, 2008). Berdasarkan informasi geologi Kota Jambi meliputi formasi Airbenakat (Tma), Muaraenim (Tmpm), Kasai (Qtk), dan endapan alluvium (Qa) yang didominasi oleh sedimen (Mangga, dkk., 1993). Kondisi geologi tersebut dapat memberikan pengaruh terhadap penjalaran gelombang seismik. Gelombang seismik akan semakin kuat ketika merambat di medium sedimen halus karena terdapat ruang antar butir yang mengakibatkan terjadinya penguatan gelombang seismik (Hartati, 2014). Hal ini dapat mengakibatkan pergerakan muka tanah yang dapat memicu kerusakan bangunan.

Salah satu upaya yang dapat dilakukan untuk mengurangi resiko akibat gempabumi adalah melakukan pemetaan indeks kerentanan seismik dan ketebalan lapisan sedimen berdasarkan respon mikrotremor. Hasil penelitian ini diharapkan mampu memberikan informasi lebih baik mengenai daerah-daerah yang rentan terhadap gempabumi. Kemudian informasi tersebut dapat dijadikan sebagai dasar dalam perencanaan dan pengembangan Kota Jambi khususnya pada daerah bagian timur yang meliputi kecamatan Danau Teluk, Jambi Selatan, Jambi Timur, Jelutung, Pal Merah, Pasar Jambi dan Pelayangan.

\section{TINJAUAN PUSTAKA}

\subsection{Geologi Daerah Penelitian}

Secara Fisiografis Kota Jambi terletak di bagian barat cekungan Sumatera Selatan yang merupakan daerah dataran rendah di sumatera timur. Dimana dibatasi Sesar Semangko dan Bukit Barisan di sebelah barat daya, Paparan Sunda di sebelah timur laut, tinggian Lampung di sebelah tenggara yang memisahkan cekungan tersebut dengan Cekungan Sunda, serta Pegu- nungan Dua Belas dan Pegunungan Tiga Puluh di sebelah barat laut yang memisahkan Cekungan Sumatra Selatan dengan Cekungan Sumatera Tengah (Wisnu dan Nazirman, 1997).

Berdasarkan peta geologi lembar Jambi maka dapat diketahui urutan pengendapan batuan di daerah penelitian ditunjukkan Gambar 1, yang dimulai dari pengendapan formasi Muaraenim (Tmpm) yang terdiri dari perselingan antara batupasir tufan dan batulempung tufan, perselingan batupasir kuarsa dan batulempung kuarsa, bersisipan batubara dan oksida besi, kemudian secara selaras di atasnya diendapkan formasi Kasai (Qtk) yang terdiri dari perselingan antara batupasir tufan dan batulempung tufan, dan endapan alluvium (Qa), yang terdiri dari kerakal, kerikil, pasir, lanau, dan lempung, terendapkan secara tidak selaras di atas permukaan Formasi Kasai (Mangga, dkk., 1993).

\subsection{Mikrotremor}

Mikrotremor merupakan getaran tanah yang sangat kecil dan terus menerus yang bersumber dari berbagai macam aktivitas manusia ataupun aktivitas alam. Mikrotremor mempunyai frekuensi lebih tinggi dari frekuensi gempabumi yaitu antara 10 hingga 20 $\mathrm{Hz}$, periodenya kurang dari 0,1 detik yang secara umum antara $0.05-2$ detik dan untuk mikrotremor periode panjang bisa 5 detik, sedang amplitudonya berkisar 0,1 - 2,0 mikron (Kanai, 1983). Gelombang yang terekam pada seismogram dapat berupa gelombang $\mathrm{P}$ dan $\mathrm{S}$ sebagai gelombang badan (body wave), serta gelombang Love dan Rayleigh sebagai gelombang permukaan (surface wave). Gelombang merambatkan energi dari sumber ke seluruh bagian bumi dan membawa informasi baik tentang sumber seismik maupun medium yang dilewatinya (Afnimar, 2009).

Hasil dari rekaman mikrotremor dapat dilihat pada Gambar 2. Getaran 
transient dapat terlihat lebih jelas dibandingkan getaran alami (stasioner). Getaran transient merupakan getaran sementara (langkah kaki manusia, mobil lewat, dll). Karena amplitudo getaran transient biasanya lebih besar dibandingkan getaran alami tanah (stasioner) (SESAME, 2004).

\subsection{Metode Hvsr}

Metode HVSR digunakan untuk mengestimasi frekuensi alami dan amplifikasi geologi setempat dari data mikrotremor (Nakamura, 2000). Metode Horizontal to Vertical Spectral Ratio (HVSR) didasarkan pada asumsi bahwa perbandingan spektrum horizontal dan vertikal dari getaran permukaan merupakan fungsi perpindahan, dapat dirumuskan sebagai berikut:

$$
\mathrm{HVSR}=\sqrt{\frac{\mathrm{S}(\text { utara-selatan })^{2}+\mathrm{S}(\text { barat-timur })^{2}}{\mathrm{~S}_{\text {vertikal }}}}
$$

\subsection{Frenkuensi Alami}

Frekuensi alami adalah nilai frekuensi alami yang menunjukkan jenis dan karakterisktik batuan tersebut. Dari nilai frekuensi alami yang terukur dipermukaan, dapat diketahui karakteristik batuan di bawahnya, hal tersebut dapat dilihat pada Tabel 1 tentang klasifikasi tanah berdasarkan nilai frekuensi alami mikrotremor oleh Kanai. Mucciarelli, dkk (2009) menyatakan nilai frekuensi natural suatu daerah dipengaruhi oleh ketebalan lapisan lapuk (h) dan kecepatan rata-rata bawah permukaan $\left(\mathrm{v}_{\mathrm{s}}\right)$, dapat dirumuskan sebagai berikut:

$f=\frac{v_{s}}{4 h}$

\subsection{Faktor Amplfikasi}

Amplifikasi merupakan perbesaran gelombang seismik yang terjadi akibat adanya perbedaan yang signifikan antar lapisan, dengan kata lain gelombang seismik akan mengalami perbesaran, jika merambat pada suatu medium ke medium lain yang lebih lunak dibandingkan dengan medium awal yang dilaluinya. Semakin besar perbedaan itu, maka perbesaran yang dialami gelombang tersebut akan semakin besar (Arifin, dkk., 2014). sehingga amplifikasi dapat dituliskan sebagai suatu fungsi perbandingan nilai kontras impedansi, yaitu:

$$
\mathrm{A}_{0}=\left[\frac{\rho_{b} \cdot v_{b}}{\rho_{s} \cdot v_{s}}\right]
$$

Menurut Laberta (2009) klasifikasi faktor amplifikasi dibagi dalam 4 zona seperti yang disajikan pada Tabel 2 .

\subsection{Indeks Kerentanan Seismik}

Indeks kerentanan seismik merupakan suatu parameter yang sangat berhubungan dengan tingkat kerawanan suatu wilayah dari ancaman resiko gempabumi (Saadudin, dkk., 2015). Menurut Nakamura (2000) indeks kerentanan seismik diperoleh dengan mengkuadratkan nilai puncak spektrum mikrotremor lalu dibagi dengan frekuensi resonansi. Secara matematis, hubungan antara indeks kerentanan seismik $(\mathrm{Kg})$, frekuensi alami $\left(f_{0}\right)$ dan faktor amplifikasi $\left(\mathrm{A}_{0}\right)$ dapat dituliskan sebagai berikut:

$$
K g=\frac{A_{0}^{2}}{f_{0}}
$$

Nilai Kg yang tinggi umumnya ditemukan pada tanah dengan litologi batuan sedimen yang lunak. Nilai yang tinggi ini menggambarkan bahwa daerah tersebut rentan terhadap gempa dan jika terjadi gempa dapat mengalami goncangan yang kuat. Menurut Refrizon, dkk. (2013) klasifikasi nilai indeks kerentanan seismik disajikan dalam Tabel 3. 


\subsection{Ketebalan Lapisan Sedimen}

Ketebalan lapisan sedimen merupakan salah satu faktor yang menyebabkan terjadinya efek tapak lokal ketika gempabumi. Efek tapak lokal merupakan bahasan tentang adanya pengaruh kondisi geologi lokal daerah sekitar terhadap getaran tanah yang terjadi akibat gempabumi. Frekuensi alami memiliki pengaruh terhadap ketebalan lapisan sedimen. Dimana frekuensi alami berbanding terbaik terhadap ketebalan lapisan sedimen. Semakin besar frekuensi alami maka semakin kecil ketebalan lapisan sedimen. Dan sebaliknya semakin kecil frekuensi alami maka semakin besar ketebalan lapisan sedimen. Hal ini karena periode dominan gelombang seismik pada suatu daerah berbanding lurus dengan ketebalan lapisan sedimen (Handayani, dkk., 2009). Secara matematis ketebalan lapisan sedimen dapat dituliskan sebagai berikut:

$h=\frac{v_{s}}{4 f_{0}}$

Dimana $v_{s}$ yang dimaksud adalah $v_{s_{30}}($ meter/sekon) berdasarkan data USGS.

\section{METODOLOGI PENELITIAN}

Penelitian ini dilaksanakan di Kota Jambi meliputi kecamatan Alam Barajo, Danau Teluk, Danau Sipin, Jambi Timur, Jambi Selatan, Jelutung, Kotabaru, Pal Merah, Pasar Jambi, Pelayangan, dan Telanaipura pada tanggal 21-30 April 2019. Peralatan yang dibutuhkan dalam penelitian ini yaitu Seismograf MAE A6000S, Seismometer, kabel penghubung, Baterai 12 Volt, GPS, Kompas, Logbook, Laptop dan Kamera. Penelitian ini diawali dengan persiapan, survey awal, pengambilan data, pengolahan dan interpretasi data. Pengambilan data dilakukan menggunakan Seismograf MAE A6000S dengan durasi 60 menit pada setiap titik pengukuran. Distribusi titik pengukuran respon mikrotremor sebanyak 25 titik secara grid tidak kaku tersebar di wilayah Kota Jambi dengan jarak antar titik pengukuran yaitu $1.98 \mathrm{~km}$. Sebaran titik pengukuran ditunjukkan oleh Gambar 3.

Hasil perekaman mikrotremor berupa data sinyal dalam format *sg2. Sinyal tersebut selanjutnya diolah menggunakan perangkat lunak Geopsy untuk mendapatkan kurva HVSR. Kurva HVSR yang diperoleh merepsentasikan nilai frekuensi alami $\left(f_{0}\right)$, faktor amplifikasi $\left(\mathrm{A}_{0}\right)$, dan standar deviasi $(\sigma)$. Berdasarkan parameter tersebut dilakukan perhitungan pemetaan nilai indeks kerentanan seismik dan ketebalan lapisan sedimen. Dalam menghitung indeks kerentanan seismik $(\mathrm{Kg})$ digunakan Persamaan 4. Sedangkan untuk menghitung ketebalan lapisan sedimen (h) dapat digunakan Persamaan 5. Setelah didapatkan nilainilai untuk setiap parameter tersebut, maka dilakukan pemetaan sebaran untuk setiap parameter menggunakan perangkat lunak ArcGis. Tahap akhir, dilakukan interpretasi kuantitatif terhadap distribusi setiap parameter mikrotremor.

\section{HASIL DAN PEMBAHASAN}

Hasil yang diperoleh dari pengolahan berupa kurva grafik HVSR seperti Gambar 4. Berdasarkan kurva tersebut diperoleh nilai frekuensi dominan tanah $\left(f_{0}\right)$ dan faktor amplifikasi $\left(\mathrm{A}_{0}\right)$ yang disajikan dalam bentuk diagram pada Gambar 5.

\subsection{Frekuensi Alami $\left(f_{0}\right)$}

Sebaran nilai frekuensi alami $\left(f_{0}\right)$ daerah penelitian berkisar antara 1.04 $3.78 \mathrm{~Hz}$. Berdasarkan distribusi nilai frekuensi alami daerah penelitian yang 
ditunjukkan oleh Gambar 6, terdapat 2 jenis frekuensi alami yaitu jenis IV dan III. Dimana berdasarkan klasifikasi Kanai dan Tanaka, jenis IV mengindikasikan ketebalan sedimen lebih dari 30 meter meliputi batuan alluvial, yang terbentuk dari sedimentasi delta, tanah atas, lumpur, dan lainnya. Jenis tersebut terdistribusi hampir pada seluruh daerah penelitian. Sedangkan jenis III mengindikasikan batuan alluvial dengan ketebalan lebih dari $5 \mathrm{~m}$ yang terdiri dari batupasir, kerikil, lempung dan lainnya. Jenis tersebut terdistribusi pada beberapa kecamatan di daerah penelitian yaitu meliputi bagian selatan Pal Merah, Jambi Selatan, Jelutung, Pasar Jambi, Danau Teluk, Pelayangan, dan bagian utara Jambi Timur.

Ditinjau dari peta geologi daerah penelitian, daerah frekuensi alami rendah berada pada endapan alluvial dan formasi muaraenim. Dimana endapan alluvial disusun oleh satuan litologi lumpur, batulempung, batupasir dan fragmen konglomerat. Sedangkan formasi muaraenim disusun oleh satuan litologi batulempung, lanau dan batupasir (Mangga, dkk., 1993).

Dalam kajian geoteknik daerah yang direkomendasikan untuk mendirikan kontruksi bangunan bertingkat seperti pembangunan pusat perbelanjaan, hotel, perkantoran atau gedung bertingkat lainnya ialah pada daerah yang memiliki nilai frekuensi alami yang tinggi. Hal ini didasarkan karena wilayah yang memiliki nilai frekuensi alami tinggi memiliki ketebalan sedimen yang lebih tipis sehingga batuan keras yang dangkal. Daerah distribusi frekuensi alami rendah berhubungan dengan geologi Kota Jambi yang didominasi endapan lunak dalam hal ini endapan alluvial.

\subsection{Faktor Amplifikasi ( $\left.A_{0}\right)$}

Sebaran nilai faktor amplifikasi $\left(\mathrm{A}_{0}\right)$ memiliki rentang nilai berkisar 1.13 4.88 kali. Berdasarkan sebaran faktor amplifikasi yang ditunjukkan oleh Gambar 7, didapatkan dua zona faktor amplikasi menurut klasifikasi pada Tabel 2 yaitu zona rendah dan zona sedang. Dimana zona rendah $\left(\mathrm{A}_{0}<3\right)$ mengindikasikan bahwa daerah tersebut disusun oleh satuan litologi yang padat. Zona tersebut terdistribusi hamper pada seluruh daerah penelitian. Sedangkan kategori sedang $\left(3<\mathrm{A}_{0}<6\right)$ mengindikasikan bahwa daerah tersebut disusun satuan geologi yang lunak. Zona tersebut terkonsentrasi di beberapa kelurahan pada daerah penelitian yaitu Tanjung Sari kecamatan Jambi Timur, Pasir Panjang, Tanjung Raden hingga bagian selatan Olak Kemang kecamatan Danau Teluk.

Jika ditinjau dari peta geologi daerah penelitian, daerah yang memiliki faktor amplifikasi yang relatif tinggi terdapat pada sebagian endapan alluvial yang sebagian besar materialnya berupa tanah lunak, lumpur, batulempung, dan batupasir (Mangga, dkk., 1993). Hal ini selaras dengan penelitian Solikhin dan Suantika (2008) bahwa lapisan tanah yang lunak dapat menyebabkan getaran gempabumi yang lebih besar dibandingkan dengan lapisan tanah yang lebih keras pada waktu dilewati oleh gelombang gempabumi. Sehingga hasil ini menunjukkan bahwa daerah yang tersusun dari litologi lunak cenderung mengalami penguatan gelombang seismik.

\subsection{Indeks Kerentanan Seismik (Kg)}

Indeks kerentanan seismik merupakan suatu parameter yang memberikan informasi tingkat kerentanan lapisan permukaan tanah saat terjadi gempabumi, sehingga dapat digunakan untuk mengetahui tinggi atau rendahnya potensi suatu wilayah mengalami kerusakan. Nilai indeks kerentanan sesimik yang tinggi diperoleh pada daerah dengan nilai amplifikasi $\left(\mathrm{A}_{0}\right)$ tinggi dan nilai frekuensi natural $\left(f_{0}\right)$ rendah. Menurut Laberta (2013) nilai 
indeks kerentanan seismik berbanding lurus dengan kerusakan bangunan yang ditimbulkan akibat bencana gempabumi. Jika suatu daerah memiliki indeks kerentanan seismik yang besar maka tingkat kesetabilan struktur tanah daerah tersebut semakin rendah, sehingga saat terjadi goncangan akibat gempabumi kemungkinan kerusakan bangunan yang terjadi akan semakin tinggi.

Berdasarkan hasil perhitungan nilai indeks kerentanan seismik $(\mathrm{Kg})$ daerah penelitian berkisar antara $0.51-20.18$ $\times 10^{-6} \mathrm{~cm}^{2} / \mathrm{s}$. Maka dari hasil perhitungan tersebut diperoleh peta distribusi indeks kerentanan seismik yang ditunjukkan oleh Gambar 8. Merujuk pada Tabel 3, didapatkan 3 zona pada daerah penelitian yaitu zona rendah dengan nilai $\mathrm{Kg}<3$, zona sedang dengan nilai $\mathrm{Kg} 3-6$, dan zona tinggi dengan nilai $\mathrm{Kg}>6$. Zona rendah mengindikasikan zona yang aman dari pergerakan muka tanah. Zona tersebut terdistribusi pada utara Danau Teluk, utara hingga barat Pelayangan, timur Jambi Timur, Pasar Jambi, dan utara Pal Merah. Zona sedang mengindikasikan zona aman dengan tingkat pergerakan muka tanah relatif kecil. Zona tersebut terdistribusi pada sebagian besar daerah penelitian meliputi Jelutung, Jambi Selatan, Jambi Timur, selatan Pal Merah, utara Danau Teluk, dan sebagian kecil di timur Pelayangan. Sedangkan zona tinggi yang mengindikasikan daerah yang rentan mengalami pergerakan muka tanah akibat gempabumi. Selaras dengan distribusi faktor amplifikasi yang bernilai relatif tinggi, zona tinggi relatif terkonsentrasi di beberapa kelurahan pada daerah penelitian yaitu Tanjung Sari kecamatan Jambi Timur, Pasir Panjang, Tanjung Raden hingga bagian selatan Olak Kemang kecamatan Danau Teluk.

Ditinjau peta geologi daerah penelitian, zona rendah hingga sedang meliputi formasi muaraenim dan kasai. Diduga litologi penyusunnya merupakan batuan yang cenderung keras meliputi batulempung tufaan, batupasir tufaan, batupasir, konglomerat, dan batulempung. Sedangkan zona tinggi di dominasi oleh alluvial yang disusun oleh litologi yang lunak seperti lumpur, batulempung, lanau dan batupasir (Mangga, dkk., 1993). Distribusi nilai indeks kerentanan seismik (Kg) ini menunjukkan ada korelasi terhadap satuan geologi pada daerah tersebut. Hal ini selaras dengan penelitian Saaddudin, dkk (2015) yang menunjukkan zona lemah berasosiasi pada kawasan yang ditutupi oleh endapan alluvial.

\subsection{Ketebalan Lapisan Sedimen (h)}

Ketebalan lapisan sedimen merupakan ketebalan lapisan lapuk pada lapisan tanah yang diendapkan di atas batuan dasar atau bedrock. Secara matematis ketebalan lapisan sedimen berbanding lurus dengan kecepatan rambat gelombang geser rata-rata dan berbanding terbalik dengan frekuensi natural.

Berdasarkan hasil perhitungan nilai ketebalan lapisan sedimen (h) daerah penelitian berkisar antara $16.46-61.45$ meter. Maka dari hasil perhitungan tersebut diperoleh peta ketebalan lapisan sedimen yang ditunjukkan oleh Gambar 9. Menurujuk pada klasifikasi Nakamura dan Tanaka, maka didapatkan 2 jenis ketebalan lapisan sedimen daerah penelitian yaitu jenis IV dengan nilai ketebalan lebih dari 30 meter dan Jenis III dengan ketebalan lapisan sedimen 10 - 30 meter. Jenis III terdistribusi pada sebagian kecamatan di daerah penelitian yang meliputi utara Danau Teluk, utara Pal Merah, barat Jambi Timur, Pasar Jambi, dan Pelayangan. Sedangkan Jenis IV terdistribusi pada sebagian daerah penelitian meliputi selatan Danau Teluk, utara Jambi Timur, Jelutung, Jambi Selatan dan bagian selatan Pal Merah.

Ditinjau dari peta geologi daerah penelitian, zona ketebalan lapisan sedimen tinggi berada pada endapan 
alluvial dan formasi muaraenim, diduga daerah tersebut disusun satuan litologi seperti batulempung, lanau dan batupasir (Mangga, dkk., 1993). Sedangkan zona ketebalan lapisan sedimen rendah berada pada formasi kasai dan sebagian endapan alluvial yang disusun oleh satuan litologi seperti tanah lunak, lumpur, batulempung, batupasir, batulempung tufaan dan batupasir tufaan (Mangga, dkk., 1993). Integrasi data geologi dan mikrotremor ini menunjukkan material endapan maupun sedimen lunak cenderung memiliki ketebalan sedimen yang relatif lebih tebal. Secara umum variasi nilai ketebalan sedimen memiliki pola yang relatif sama dengan karakteristik geologi daerah penelitian. Selain itu juga dipengaruhi oleh faktor topografi dan variasi kecepatan gelombang geser pada daerah penelitian.

\subsection{Hubungan Indeks Kerentanan Seismik dan Ketebalan Lapisan Sedimen}

Integrasi distribusi indeks kerenantanan seismik dan distribusi ketebalan lapisan sedimen menunjukkan keselarasan. Dimana distribusi indeks kerentanan seismik rendah dengan rentang nilai berkisar $0.70-3.00 \times 10^{-6}$ $\mathrm{cm}^{2} / \mathrm{s}$ relatif berkolerasi dengan ketebalan lapisan sedimen dengan rentang nilai berkisar 16.46 - 30.00 meter. Sedangkan indeks kerentanan seismik sedang hingga tinggi dengan rentang nilai berkisar $3.01-20.18 \times 10^{-6}$ $\mathrm{cm}^{2} / \mathrm{s}$ relatif berkolerasi dengan ketebalan sedimen yang lebih tebal 30.01 - 60.45 meter. Sehingga ketebalan lapisan sedimen memberikan pengaruh terhadap tinggi atau rendahnya indeks kerentanan seismik.

Berdasarkan korelasi ketebalan lapisan sedimen dengan indeks kerentanan seismik menunjukkan nilai korelasi $\mathrm{R}=0.63$ (Gambar 10). Dari hasil tersebut menujukkan hubungan yang relatif kuat antara ketebalan lapisan sedimen dengan indeks kerentanan seismik. Dengan kata lain hasil ini menunjukkan bahwa sebagian besar nilai ketebalan lapisan sedimen relatif semakin tinggi terhadap kenaikan nilai indeks kerentanan seismik. Hal tersebut berkaitan dengan kondisi geologi Kota Jambi bagian timur yang sebagian besar berumur kuarter merupakan endapan aluvial.

\section{KESIMPULAN DAN SARAN}

\subsection{Kesimpulan}

Berdasarkan hasil analisa penelitian yang telah dilakukan, maka diperoleh kesimpulan sebagai berikut:

1. Distribusi nilai indeks kerentanan seismik (Kg) menunjukkan zona tinggi relatif berakumulasi pada endapan alluvial. Daerah tersebut berada pada kelurahan Tanjung Sari kecamatan Jambi Timur, Pasir Panjang, Tanjung Raden hingga bagian selatan Olak Kemang kecamatan Danau Teluk.

2. Hasil distribusi indeks kerenantanan seismik dan distribusi ketebalan lapisan sedimen menunjukkan keselarasan. Dimana distribusi indeks kerentanan seismik rendah dengan rentang nilai berkisar $0.70-3.00 \times$ $10^{-6} \mathrm{~cm}^{2} / \mathrm{s}$ relatif berkolerasi dengan ketebalan lapisan sedimen dengan rentang nilai berkisar $16.46-30.00$ meter. Sedangkan indeks kerentanan seismik sedang hingga tinggi dengan rentang nilai berkisar $3.01-20.18 \times$ $10^{-6} \mathrm{~cm}^{2} / \mathrm{s}$ relatif berkolerasi dengan ketebalan sedimen yang lebih tebal $30.01-60.45$ meter.

\subsection{Saran}

Adapun saran untuk penelitian selanjutnya dibutuhkan data pendukung seperti data bor untuk mengetahui litologi daerah penelitian secara tepat pada setiap lapisan sehingga hasil yang didapatkan diharapkan mampu memberikan hasil yang lebih akurat. 


\section{UCAPAN TERIMA KASIH}

Dalam penyusunan jurnal ini penulis menyampaikan rasa terima kasih kepada kedua orang tua dan keluarga tercinta yang selama ini telah memberikan dukungan moril dan meteril. Dan seluruh pihak yang turut membantu dalam penelitian ini sehingga penelitian ini dapat terlaksana.

\section{DAFTAR PUSTAKA}

Arifin, S. S., Mulyatno, B. S., Marjiyono dan Setianegara, R., 2014, Penentuan Zona Rawan Guncangan Bencana Gempabumi Berdasarkan Analisis Nilai Amplifikasi HVSR Mikrotremor dan Analisis Periode Dominan Daerah Liwa dan Sekitarnya, Jurnal Eksplorasi Geofisika, No. 02, Vol. 01, hal. 3040.

Edwiza, D., dan Novita, S., 2008, Pemetaan Percepatan Tanah Maksimum dan Intensitas Seismik Kota Padang Panjang Menggunakan Metoda Kanai, Jurnal Teknika, No. 29, Vol. 02, hal. 111118.

Handayani, L., Mulyadi, D., Wardhana, D.D., dan Nur, W.H., 2009. Percepatan Pergerakan Tanah Maksimum Daerah Cekungan Bandung: Studi Kasus Gempa Sesar Lembang. Jurnal Geologi dan Sumberdaya Mineral, No. 05, Vol 19, hal. 333-337.

Hartati, L., 2014, Pemetaan Tingkat Resiko Gempabumi Daerah Liwa dan Sekitarnya Berdasarkan Pengukuran Mikrotremor, Tesis, Program Studi Magister Fisika, Universitas Gajah Mada, Yogyakarta.
Kanai, K., 1983, Seismology in Engineering, Tokyo University, Japan.

Laberta, S., 2013, Mikrozonasi Indeks Kerentanan Seismik Berdasarkan Analisis Mikrotremor di Kecamatan Jetis, Kabupaten Bantul, Daerah Istimewa Yogyakarta, Skripsi, Program Studi Fisika, Universitas Negeri Yogyakarta, Yogyakarta.

Mangga, S.A., Santoso, S., dan Herman, B., 1993, Peta Geologi Lembar Jambi Sumatera. Pusat Penelitian dan Pengembangan Geologi, Bandung.

Nakamura, $\quad$ Y., 2000, Clear Indentification of Fundamental Idea of Nakamura's Technique and Its Application, Tokyo University, Japan.

Pemerintah Kota Jambi, 2018, Kecamatan dan Kelurahan, diakses tgl 03 September 2018.

Refrizon, Hadi, A.I., Lestari, K. dan Oktari, T., 2013, Analisis Percepatan Tanah Maksimum dan Tingkat Kerentanan Seismik Daerah Ratu Agung Kota Bengkulu, Prosiding Semirata FMIPA, Universitas Lampung, Lampung.

Saaduddin, Sismanto dan Marjiyono, 2015, Pemetaan Indeks Kerentanan Seismik Kota Padang Sumatera Barat dan Korelasinya dengan Titik Kerusakan Gempabumi 30 September 2009, Jurnal Kebumian Ke-8, hal. 459-466, Universitas Gajah Mada, Yogyakarta.

SESAME, 2004, Guidelines for The Implementation of the H/V Spectral Ratio Technique on Ambient Vibrations: Measurement, 
Processing and Interpretation, SESAME Europe Research Project.

Solikhin, A., dan Suantika, G., 2008, Laporan Penyelidikan Gempabumi Daerah Kabupaten Bandung dan Sekitarnya Jawa Barat, Pusat
Vulkanologi dan Mitigasi Bencana Geologi, Bandung.

Wisnu, dan Nazirman, 1997, Geologi Regional Sumatera Selatan, Pusat Survei Geologi, Badan Geologi Kementerian ESDM, Bandung.

\section{LAMPIRAN}

Tabel 1. Klasifikasi Tanah Berdasarkan Nilai Frekuensi Alami Mikrotremor Oleh Kanai (Arifin, dkk., 2014)

\begin{tabular}{|c|c|c|c|c|}
\hline \multicolumn{2}{|c|}{$\begin{array}{c}\text { Klasifikasi } \\
\text { Tanah }\end{array}$} & \multirow{2}{*}{$\begin{array}{c}\text { Frekuensi } \\
\text { Alami (Hz) }\end{array}$} & \multirow[t]{2}{*}{ Klasifikasi Kanai } & \multirow[t]{2}{*}{ Deskripsi } \\
\hline Tipe & Jenis & & & \\
\hline \multirow{2}{*}{ IV } & $\mathrm{I}$ & $6.67-20.0$ & $\begin{array}{l}\text { Batuan tersier atau lebih tua. } \\
\text { Terdiri dari batuan hard } \\
\text { sandy, gravel, dan lainnya. }\end{array}$ & $\begin{array}{c}\text { Ketebalan sedimen } \\
\text { permukaannya sangat tipis, } \\
\text { didominasi oleh batuan keras, } \\
\text { lebih kecil dari } 5 \text { meter. }\end{array}$ \\
\hline & II & $4.0-10.0$ & $\begin{array}{l}\text { Batuan alluvial dengan } \\
\text { ketebalan } 5 \mathrm{~m} \text {. Terdiri dari } \\
\text { sandy-gravel, sandy hard } \\
\text { clay, loam, dan lainnya. }\end{array}$ & $\begin{array}{c}\text { Ketebalan sedimen } \\
\text { permukaannya masuk dalam } \\
\text { kategori menengah 5-10 } \\
\text { meter. }\end{array}$ \\
\hline III & III & $2.5-4.0$ & $\begin{array}{c}\text { Batuan alluvial dengan } \\
\text { ketebalan lebih dari } 5 \mathrm{~m} \text {. } \\
\text { Terdiri dari sandy-gravel, } \\
\text { sandy hard clay, loam, dan } \\
\text { lainnya. }\end{array}$ & $\begin{array}{l}\text { Ketebalan sedimen permukaan } \\
\text { masuk dalam kategori tebal, } \\
\text { sekitar 10-30 meter. }\end{array}$ \\
\hline II & \multirow{2}{*}{ IV } & \multirow{2}{*}{$<2.5$} & \multirow{2}{*}{$\begin{array}{c}\text { Batuan alluvial, yang } \\
\text { terbentuk dari sedimentasi } \\
\text { delta, top soil, lumpur, dan } \\
\text { lainnya. Dengan kedalaman } \\
30 \mathrm{~m} \text { atau lebih. }\end{array}$} & \multirow{2}{*}{$\begin{array}{c}\text { Ketebalan sedimen } \\
\text { permukaannya sangatlah tebal, } \\
\text { lebih dari } 30 \text { meter. }\end{array}$} \\
\hline I & & & & \\
\hline
\end{tabular}

Tabel 2. Klasifikasi Nilai Faktor Amplifikasi (Laberta, 2009)

\begin{tabular}{|c|c|c|}
\hline Zona & Klasifikasi & Nilai faktor amplifikasi \\
\hline 1 & Rendah & $\mathrm{A}<3$ \\
\hline 2 & Sedang & $3<\mathrm{A}<6$ \\
\hline 3 & Tinggi & $6<\mathrm{A}<9$ \\
\hline 4 & Sangat Tinggi & $\mathrm{A}<9$ \\
\hline
\end{tabular}

Tabel 3. Klasifikasi Nilai Indeks Kerentanan Seismik (Refrizon, dkk., 2013)

\begin{tabular}{|c|c|c|}
\hline Zona & Klasifikasi & Nilai Kg \\
\hline 1 & Rendah & $\mathrm{Kg}<3$ \\
\hline 2 & Sedang & $3<\mathrm{Kg}<6$ \\
\hline 3 & Tinggi & $>6$ \\
\hline
\end{tabular}




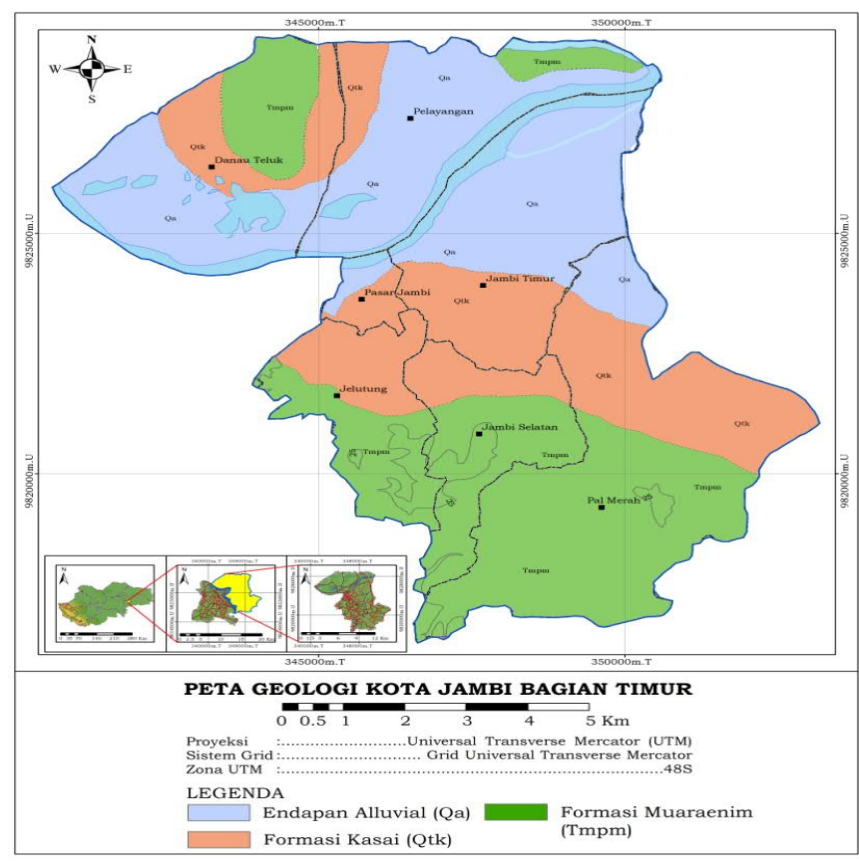

Gambar 1. Peta Geologi Kota Jambi Bagian Timur (Mangga, dkk., 1993)

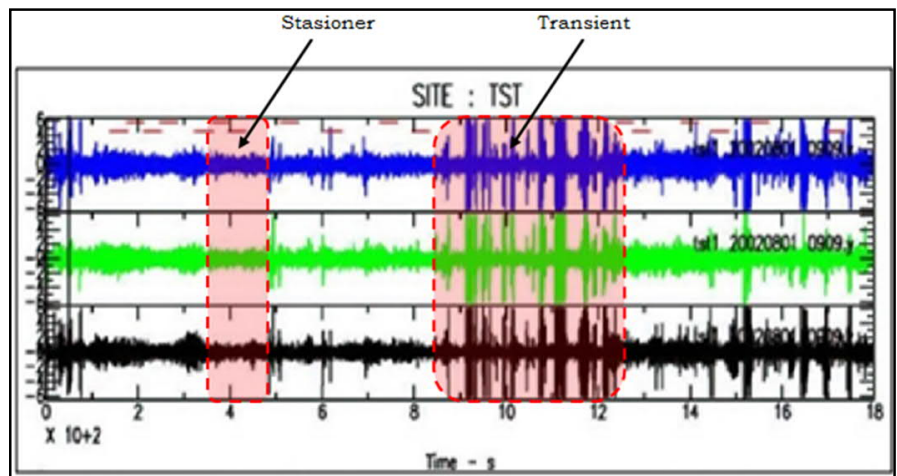

Gambar 2. Ilustrasi Rekaman Mikrotremor (SESAME, 2004)

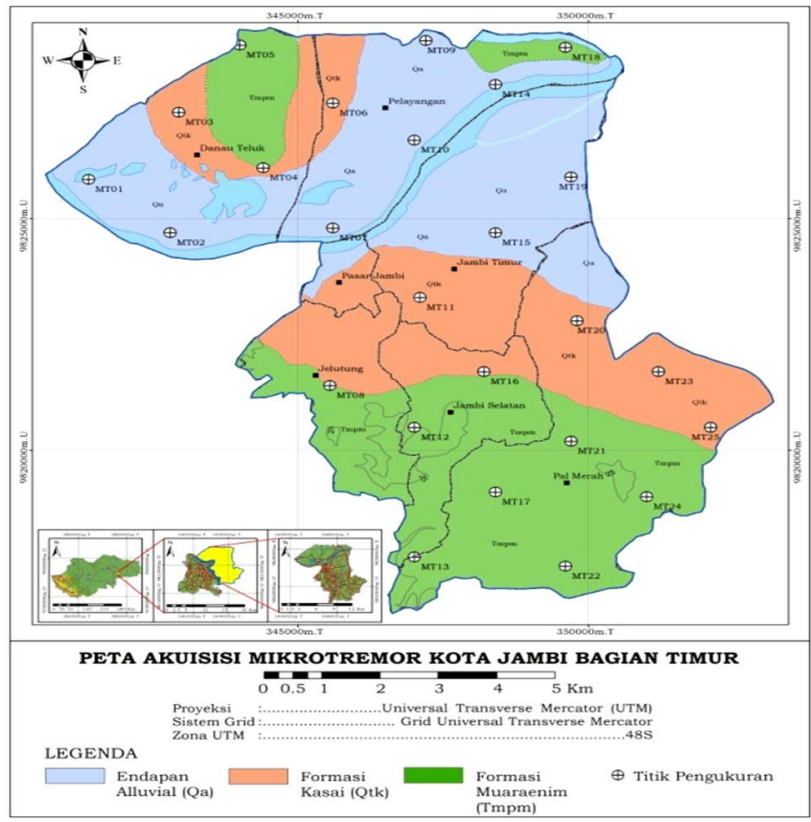

Gambar 3. Peta Akuisisi Mikrotremor Kota Jambi Bagian Timur 


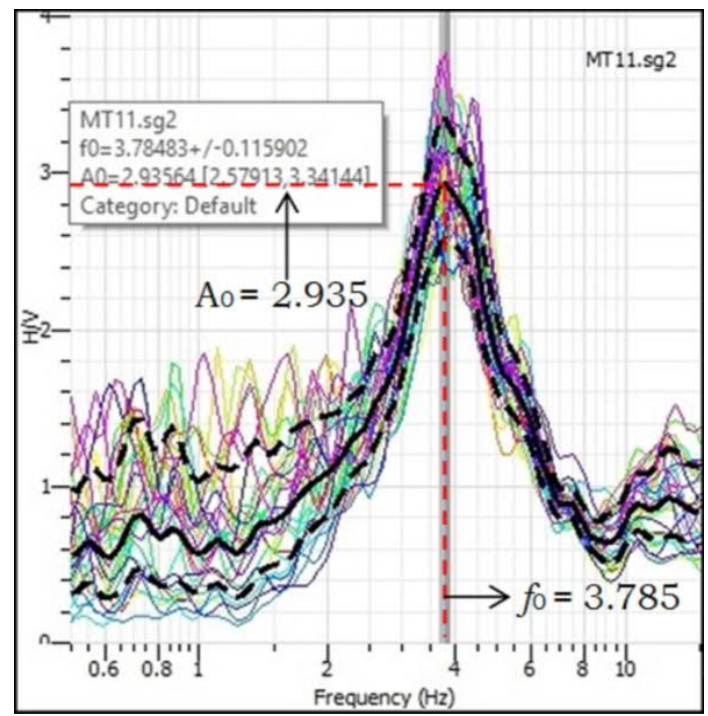

Gambar 4. Kurva H/V pada Titik MT11

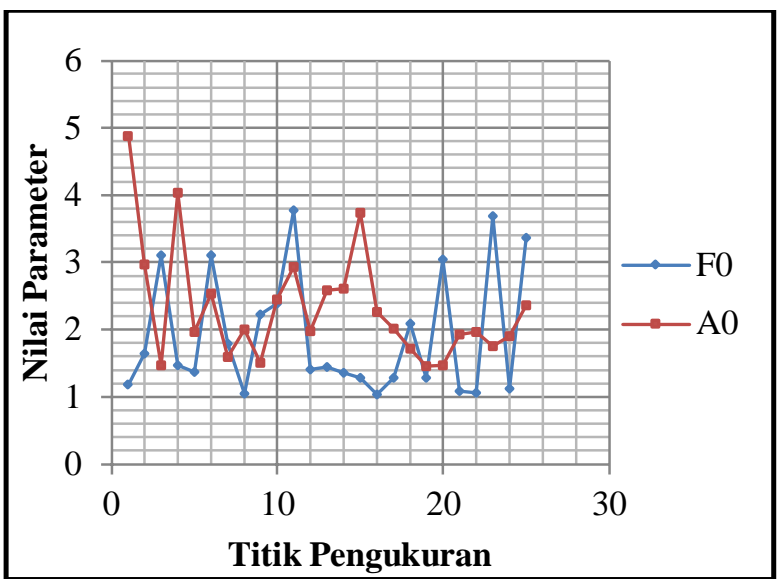

Gambar 5. Nilai Frekuensi Alami dan Faktor Amplifikasi

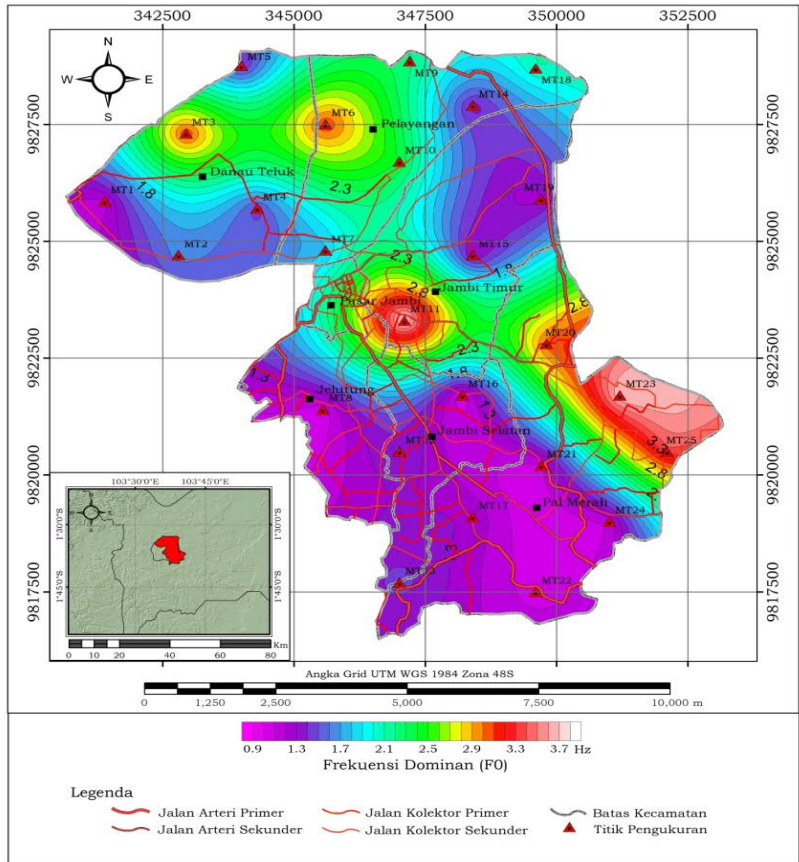

Gambar 6. Peta Distribusi Frekuensi Alami Kota Jambi Bagian Timur 


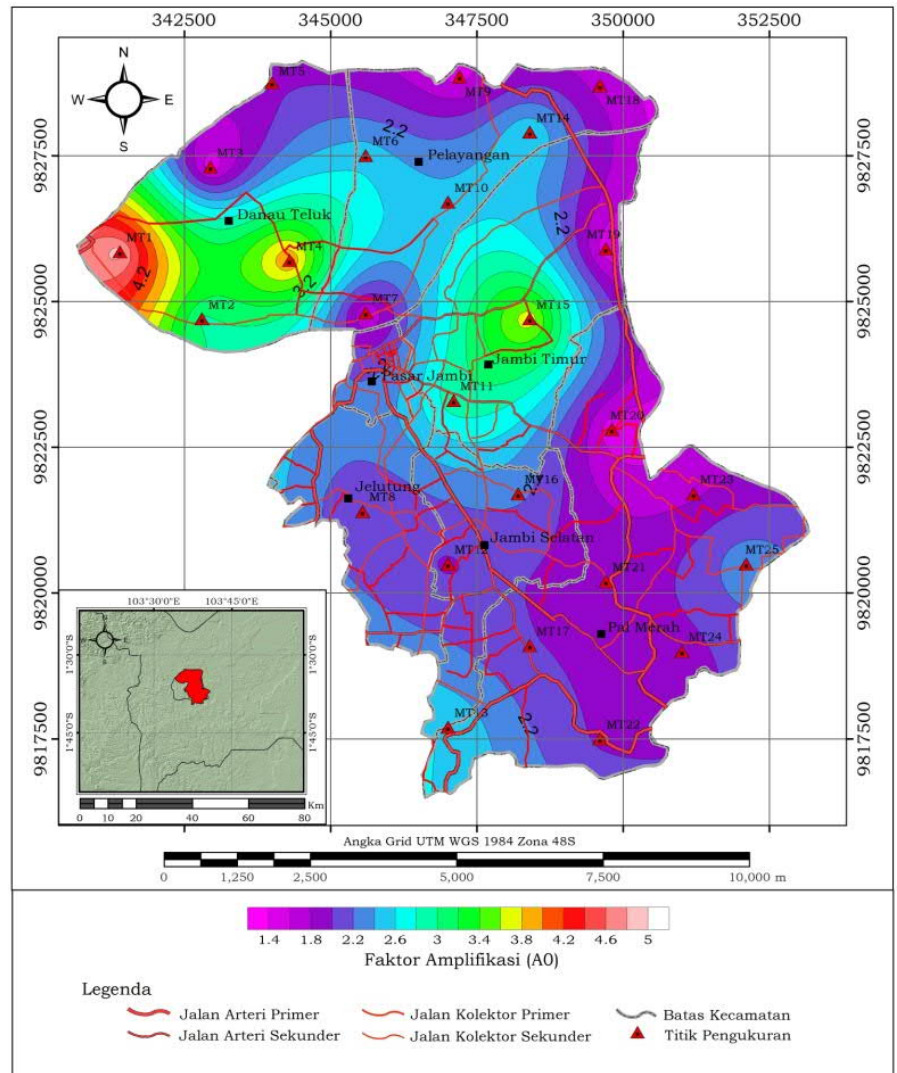

Gambar 7. Peta Distribusi Faktor Amplifikasi Kota Jambi Bagian Timur

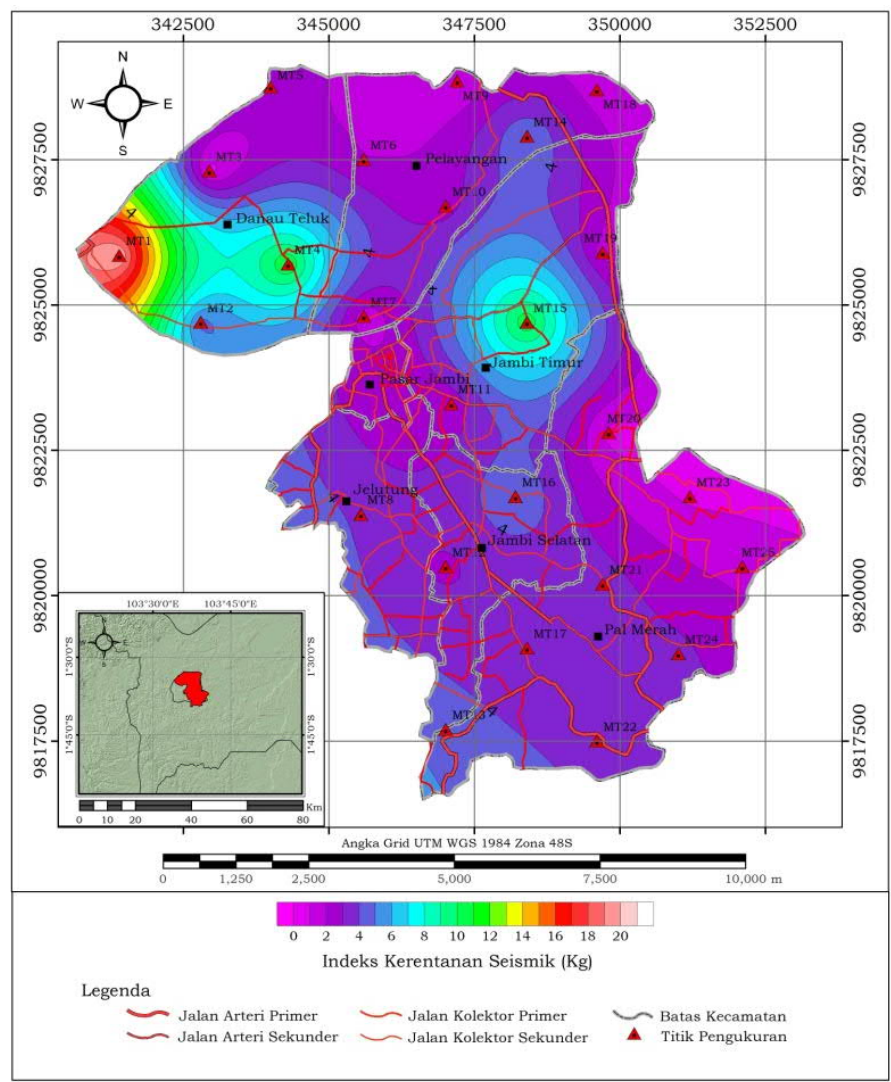

Gambar 8. Peta Distribusi Indeks Kerentanan Seismik Kota Jambi Bagian Timur 


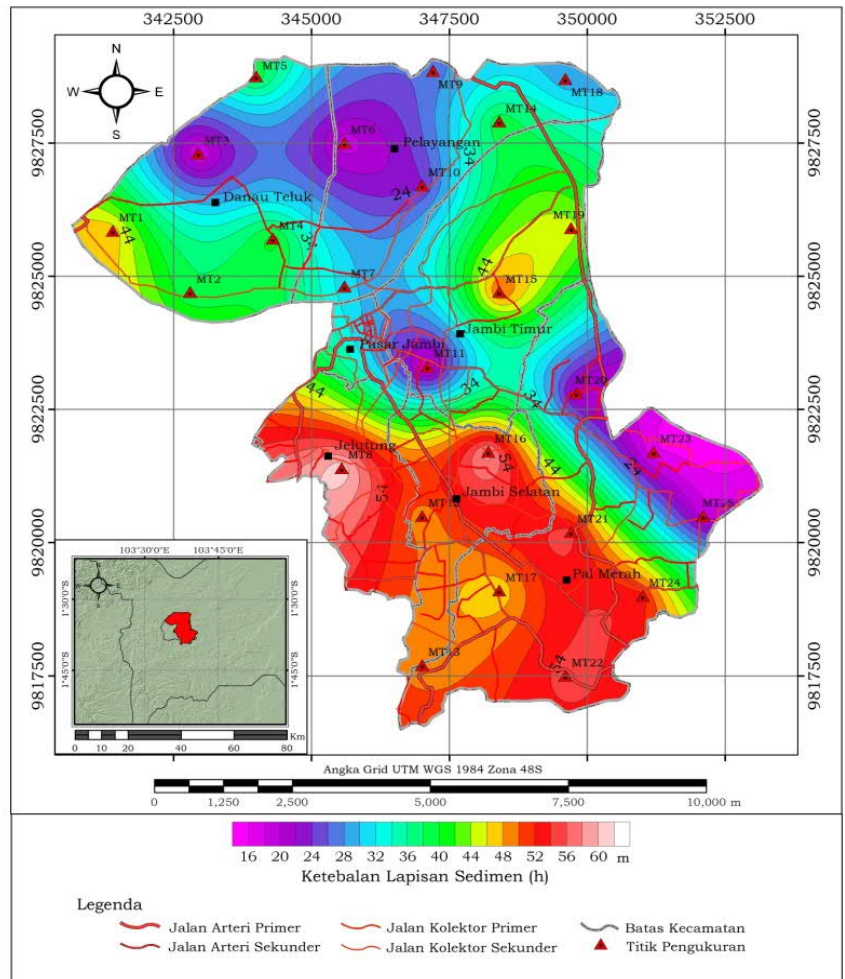

Gambar 9. Peta Distribusi Ketebalan Lapisan Sedimen Kota Jambi Bagian Timur

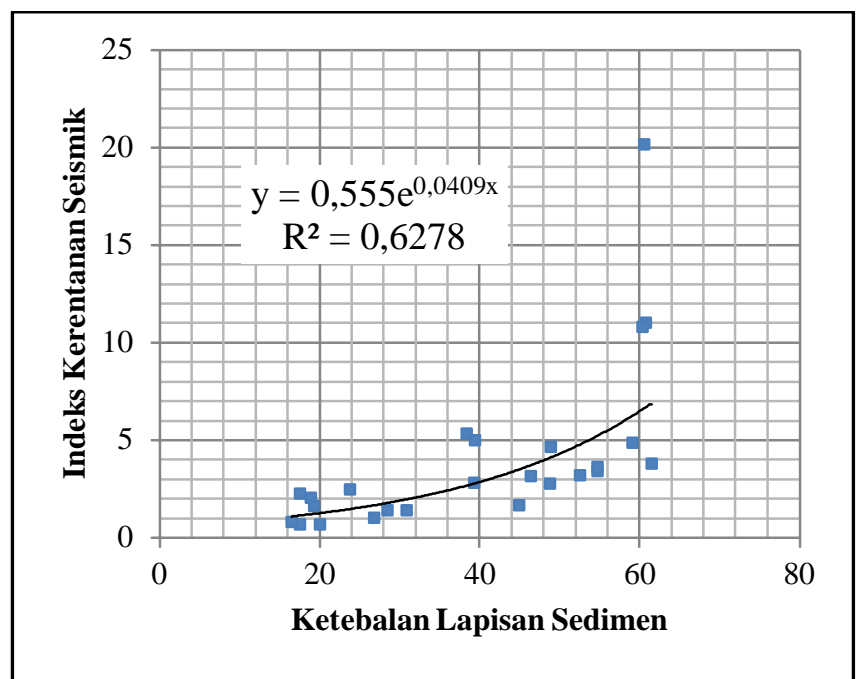

Gambar 10. Grafik Hubungan Ketebalan Lapisan Sedimen dengan Indeks Kerentanan Seismik 